\title{
Myocarditis presenting as variant angina: a rare presentation
}

Amole O. Ojo, Chhaya A. Gupta, Anthon Fuisz, Zeeshan Solangi, Prakash Harikrishnan, Howard A. Cooper, Julio A. Panza, Wilbert S. Aronow

Department of Medicine, Division of Cardiology, Westchester Medical Center/ New York Medical College, Valhalla, NY, USA

Submitted: 2 August 2016

Accepted: 28 September 2016

Arch Med Sci 2018; 14, 5: 1175-1179

DOI: https://doi.org/10.5114/aoms.2017.68931

Copyright @ 2017 Termedia \& Banach

Myocarditis is inflammation of the myocardium caused by an infectious or autoimmune process. Myocarditis may present with a broad range of symptoms, ranging from mild shortness of breath or chest pain that resolves without specific therapy to cardiogenic shock and death [1]. Myocarditis presents very rarely as variant angina pectoris due to coronary artery spasm.

A 45-year-old man with no significant past medical history other than a recent urinary tract infection presented to the emergency department (ED) with substernal chest pain. The chest pain was described as a substernal pressure which lasted for $45 \mathrm{~min}$ and was associated with a feeling of doom. There were no known aggravating or alleviating factors. He had no known cardiovascular risk factors and he denied recent use of recreational drugs. His system review was positive for dysuria and diarrhea. The blood pressure was $123 / 79 \mathrm{~mm} \mathrm{Hg}$, the heart rate was $76 \mathrm{bpm}$, and the respiratory rate was $14 / \mathrm{min}$. The patient was afebrile. The oxygen saturation was $99 \%$ on room air. Physical examination including cardiovascular examination was normal.

The electrocardiogram (ECG) showed sinus rhythm with ST-segment elevation in the inferior and anterolateral leads (Figure 1). A preliminary diagnosis of ST-segment elevation myocardial infarction (STEMI) was made, and the patient was taken immediately to the cardiac catheterization laboratory. Coronary angiography showed normal coronary arteries (Figures $2 \mathrm{~A}$, $B)$. The chest pain completely resolved and the patient was admitted to the coronary care unit. Transthoracic echocardiography demonstrated a normal left ventricular ejection fraction (60\%) and no regional wall motion abnormalities. A repeat ECG obtained one hour after coronary angiography showed near complete resolution of the ST-segment elevation (Figure 3).

Seven hours later, the patient developed another episode of chest pain. The ECG then showed increased ST-segment elevation in the inferior and anterolateral leads (Figure 4). The chest pain and ECG changes quickly resolved after treatment with sublingual nitroglycerin (Figure 5). A diagnosis of coronary artery spasm was made.

The urine drug screen was negative. Abnormal laboratory findings included a white blood cell count of $24,800 / \mathrm{mm}^{3}$, a cardiac troponin I which peaked at $21.01 \mu \mathrm{g} / \mathrm{ml}$ (cut off value in our laboratory $0.02 \mu \mathrm{g} / \mathrm{ml}$ ), and a creatine kinase MB fraction which peaked at $125.1 \mathrm{IU} / \mathrm{l}$ (cut off in our laboratory value $6.6 \mathrm{IU} / \mathrm{l})$. Cardiac magnetic resonance imaging (MRI) obtained on the third hospital day showed epicardial enhancement along

\author{
Corresponding author: \\ Prof. Wilbert S. Aronow MD, \\ FACC, FAHA \\ Cardiology Division \\ New York Medical College \\ Macy Pavilion \\ Room 141 \\ Valhalla, NY 10595 \\ Phone: (914) 493-5311 \\ Fax: (914) 235-6274 \\ E-mail:wsaronow@aol.com
}




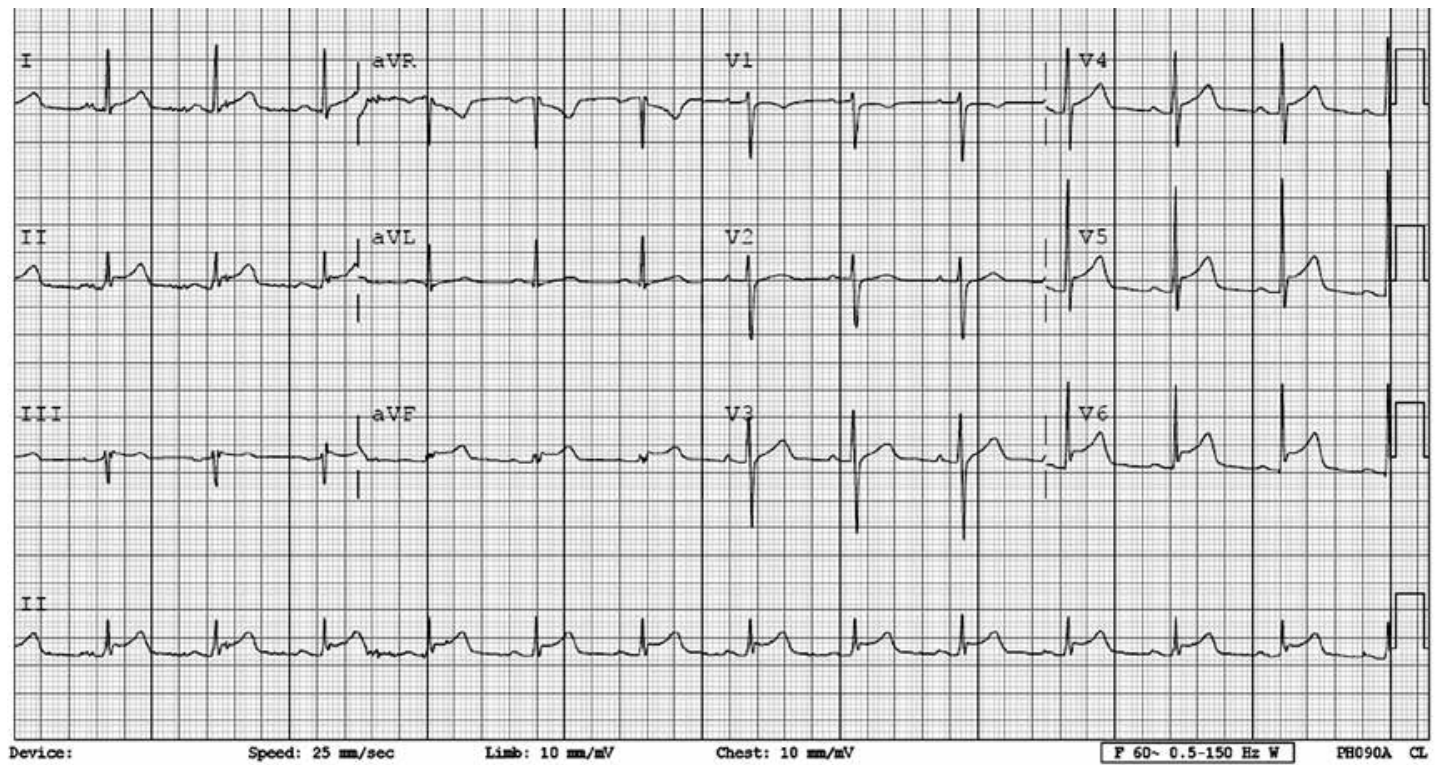

Figure 1. ECG showing sinus rhythm with ST-segment elevation in the inferior and anterolateral leads
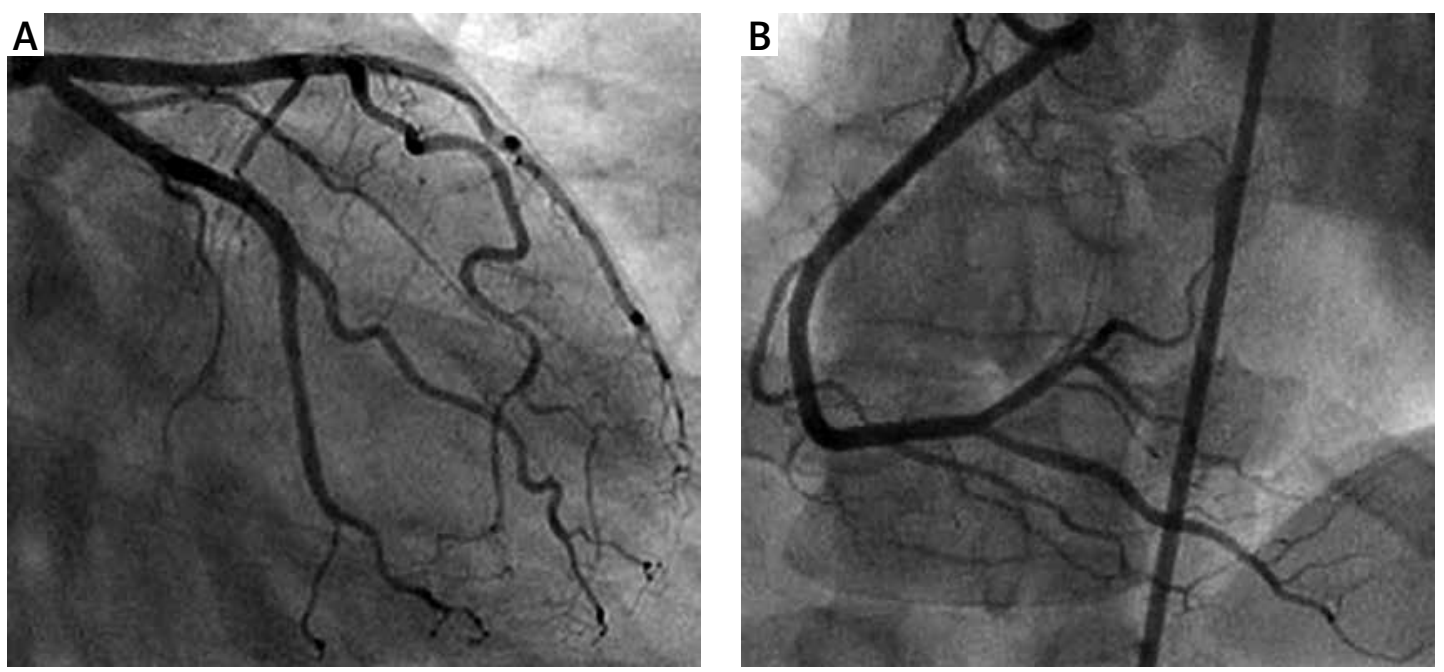

Figure 2. Coronary angiogram showing normal left (A) and right (B) coronary arteries, respectively

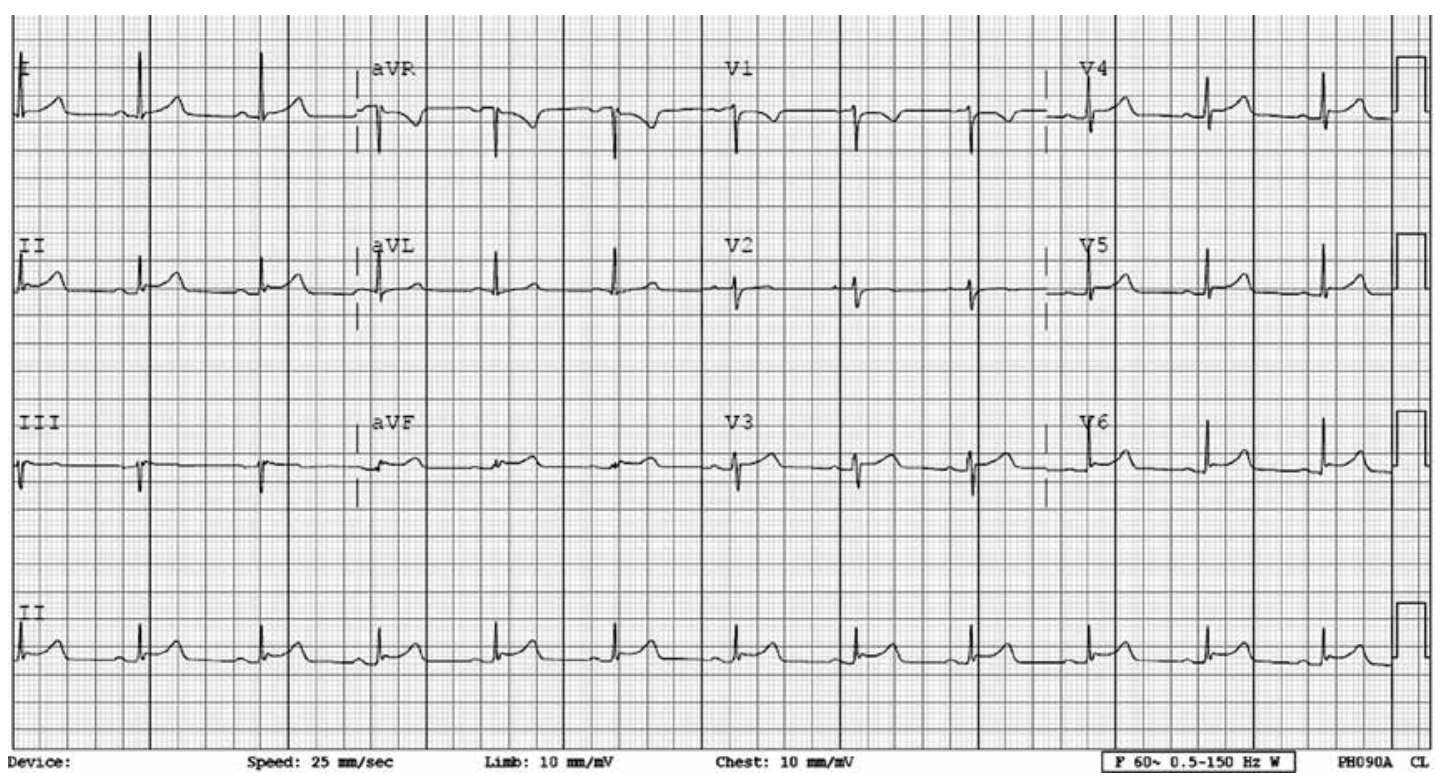

Figure 3. Repeat ECG showing near complete resolution of ST-segment elevation 


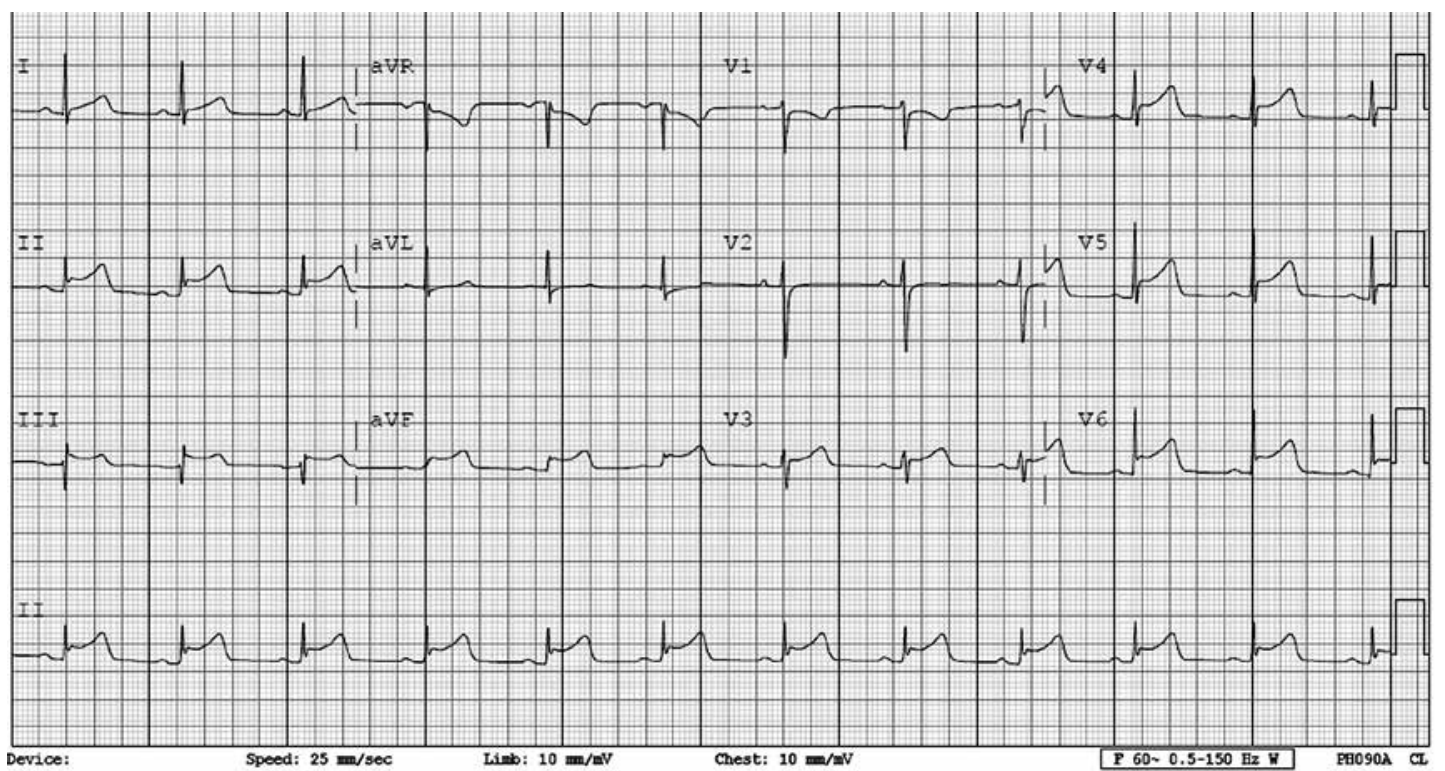

Figure 4. ECG showing increased ST-segment elevation in the inferior and anterolateral leads after the patient developed another episode of chest pain

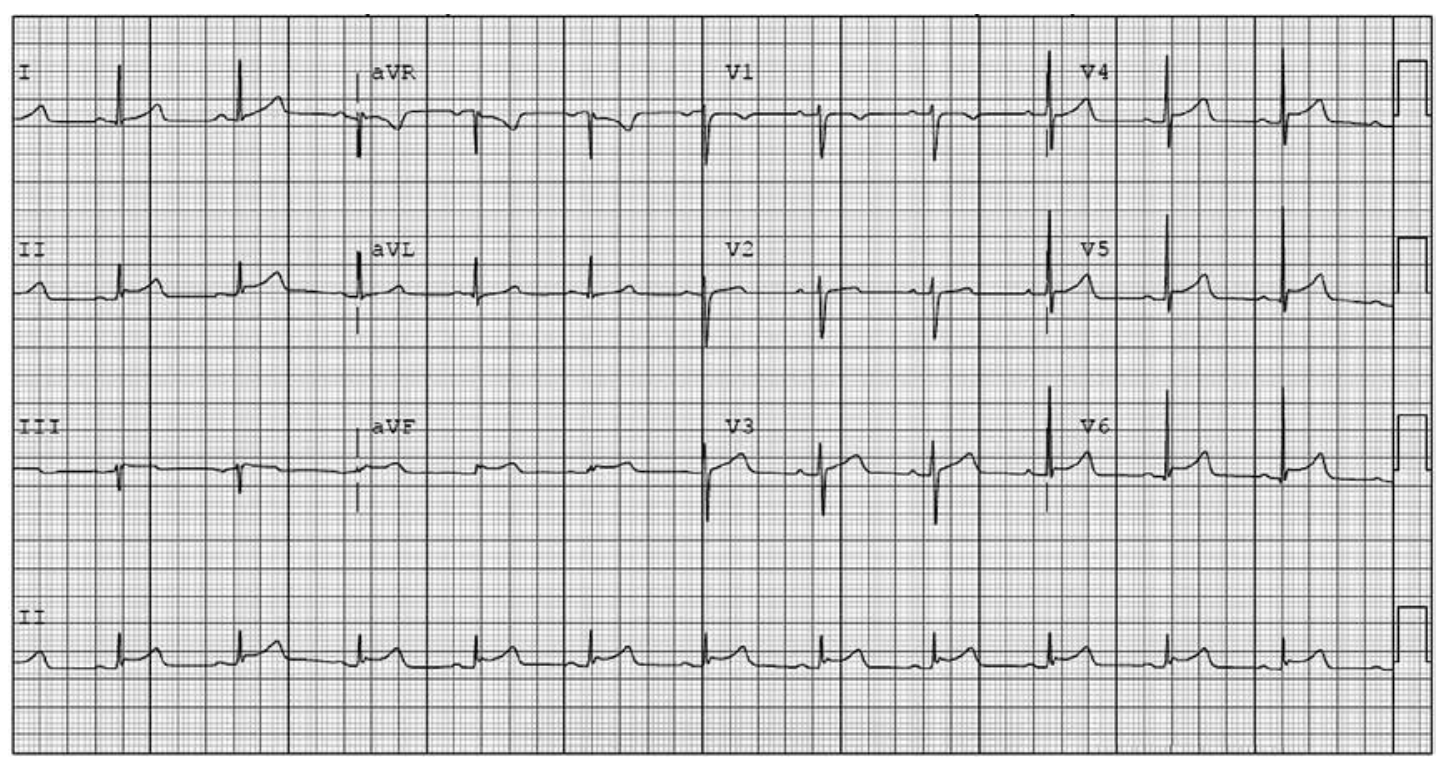

Figure 5. ECG after resolution of the chest pain showed near normalization of the ST-segment elevation in the inferior and anterolateral leads

the lateral wall consistent with myocarditis with no evidence of infarction (Figures 6 A, B). No evidence of edema was detected by T2FS sequences. The cardiac MRI also showed mild hypokinesis of the lateral wall with a left ventricular ejection fraction of $57 \%$. The patient's subsequent hospital course was uneventful. The ECG on the day of discharge (day 4 of hospitalization) showed minor T-wave changes in the distribution of prior ST-segment elevation (Figure 7).

Myocardial infarction (MI) may occur in approximately $25 \%$ of untreated patients with vasospastic angina pectoris. However, MI is usually associated with concurrent obstructive coronary artery disease (CAD). In this patient with elevated cardiac enzymes but normal coronary arteries, we suspected myocarditis. Cardiac MRI confirmed this diagnosis.

Myocarditis can present with chest pain and ST-segment elevation on the ECG and is often misdiagnosed as STEMI until coronary angiography demonstrates normal or non-obstructive coronary arteries. Of 41 patients with acute myocarditis confirmed by cardiac MRI, 39\% had ST-segment elevation on the ECG [2]. In a systematic review, of 1676 patients presenting with suspected $\mathrm{MI}$ and non-obstructive coronary arteries, $33 \%$ of these patients had myocarditis [3]. The ST-segment el- 

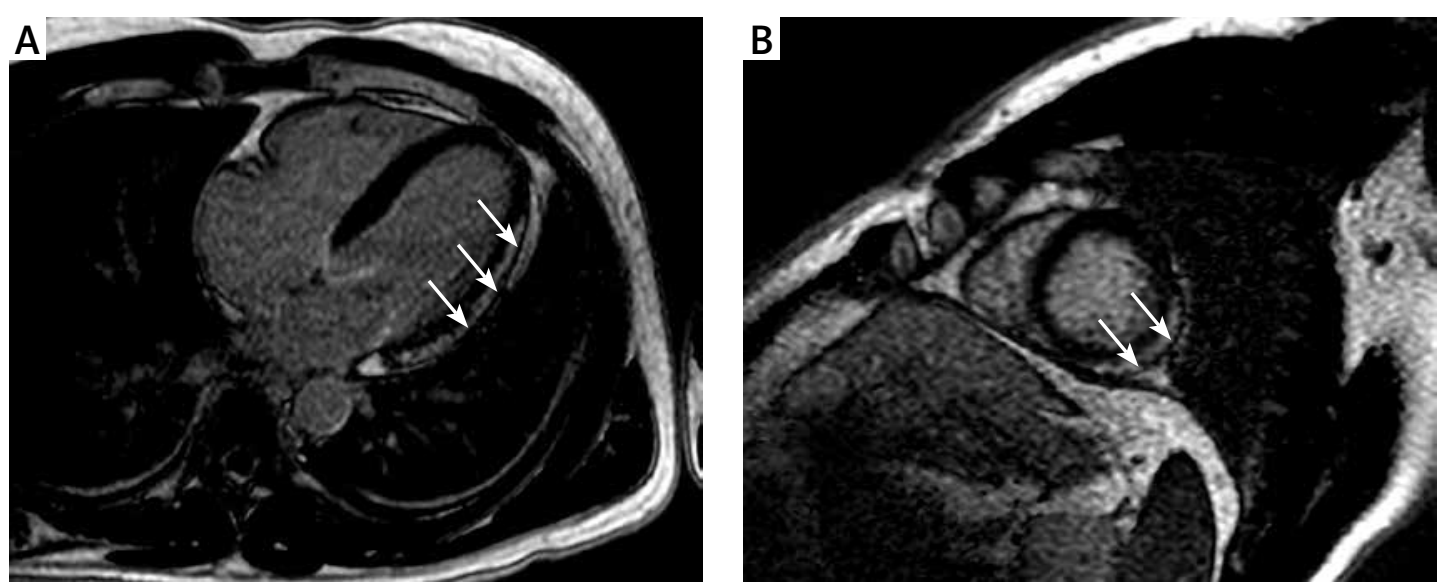

Figures 6 A, B. Cardiac magnetic resonance image showing epicardial enhancement along the lateral wall consistent with myocarditis

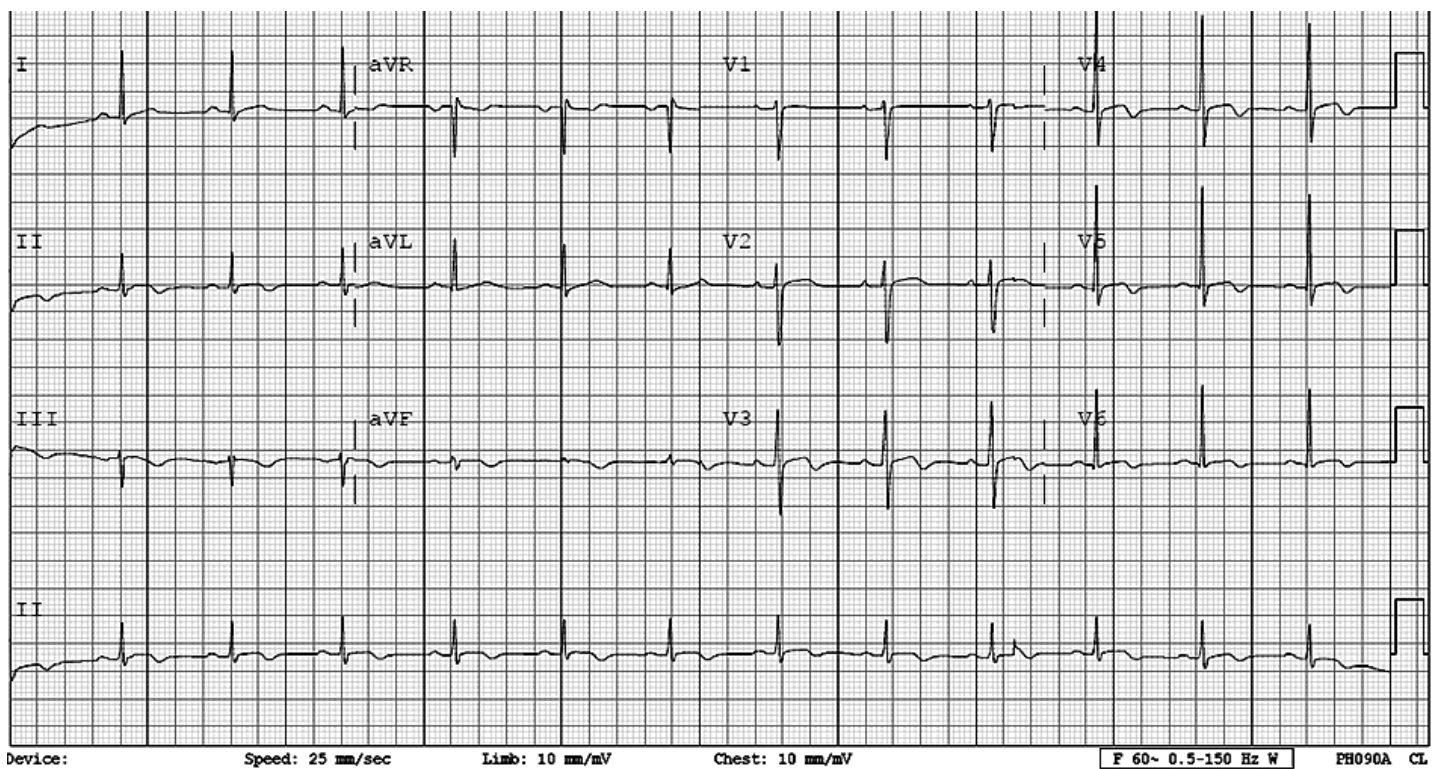

Figure 7. ECG on the day of discharge (day 4 of hospitalization) showed almost complete resolution of the ST-segment elevation

evations that accompany myocarditis are usually persistent and not dynamic. This has often been attributed to associated pericardial inflammation or direct inflammatory reaction in the myocardium. However, seven cases have been reported with dynamic ST-segment changes, which are indicative of coronary artery spasm causing chest pain in myocarditis [4-10]. In two of these cases of myocarditis, coronary artery spasm was demonstrated angiographically $[9,10]$. Although we did not demonstrate coronary artery spasm angiographically, sudden chest pain at rest, accompanied by ST-segment elevation that resolves with nitroglycerin is the sine qua non of vasospastic angina pectoris. Coronary artery spasm in myocarditis may be due to vasoactive substances such as thromboxane A2 that are released by platelet aggregations formed as a result of coronary arteritis $[7,11]$. This has been reported in cases of myocarditis caused by infection with parvovirus B19 [10].
In conclusion, we report a rare case of myocarditis presenting as vasospastic angina pectoris. Clinicians need to consider myocarditis when a patient with presumed myocardial infarction is found to have normal coronary arteries.

\section{Conflict of interest}

The authors declare no conflict of interest.

\section{References}

1. Cooper LT Jr. Myocarditis. N Engl J Med 2009; 360: 1526-38.

2. Jhamnani S, Fuisz A, Lindsay J. The spectrum of electrocardiographic manifestations of acute myocarditis: an expanded understanding. J Electrocardiol 2014; 47: 941-7.

3. Pasupathy S, Air T, Dreyer RP, et al. Systematic review of patients presenting with suspected myocardial infarction and non-obstructive coronary arteries. Circulation 2015; 131: 861-70. 
4. Silva D, Marques P, Martins S, et al. Coronary artery vasospasm and acute myocarditis: a rare association. Rev Port Cardiol 2010; 29: 1879-88.

5. Kumar A, Bagur R, Béliveau P, et al. Acute myocarditis triggering coronary spasm and mimicking acute myocardial infarction. World I Cardiol 2014; 6: 1045-8.

6. McCully RB, Cooper LT, Schreiter S, et al. Coronary artery spasm in lymphocytic myocarditis: a rare cause of acute myocardial infarction. Heart 2005; 91: 202.

7. Ferguson DW, Farwell AP, Bradley WA, et al. Coronary artery vasospasm complicating acute myocarditis - a rare association. West J Med 1988; 148: 664-9.

8. Elmahy H, Abdelbar A, Schmitt M. Striking temporally dynamic ECG changes associated with recurrent chest pain in a case of myopericarditis. BMJ Case Rep 2013; pii: bcr2013010012.

9. Iwasaki K, Kusachi S, Tominaga Y, et al. Coronary artery spasm demonstrated by coronary angiography in a patient with acute myocarditis resembling acute myocardial infarction: a case report. Jpn J Med 1991; 30: 573-7.

10. Yilmaz A, Mahrholdt H, Athanasiadis A, et al. Coronary vasospasm as the underlying cause for chest pain in patients with PVB19 myocarditis. Heart 2008; 94: 1456-63.

11. Robertson RM, Robertson D, Friesinger GC, et al. Platelet aggregates in peripheral and coronary sinus blood in patients with spontaneous coronary artery spasm. Lancet 1980; 2: 829-31. 